\title{
Is PSMA PET a necessity in oligo-metastatic recurrent prostate cancer?
}

\author{
Hampson $\mathrm{A}^{1}$, Rai $\mathrm{BP}^{2}$ and Vasdev $\mathrm{N}^{1,3 *}$ \\ ${ }^{1}$ Department of Urology, Lister Hospital, Stevenage, UK \\ ${ }_{2}^{2}$ James Cook University Hospital, Middlesbrough, UK \\ ${ }^{3}$ School of Life and Medical Sciences, University of Hertfordshire, Hatfield, UK
}

Positron Emission Tomography (PET) nuclear imaging is vital in the process of diagnosing recurrence of prostate cancer following radical therapy. The conventional PET modality uses Choline based tracers (11C or $18 \mathrm{~F}$ ), a phospholipid precursor that becomes concentrated in areas of high cell division and thus highlights areas of malignancy. This is the current form of gold standard imaging for prostate cancer recurrence, however, multiple studies have found that it's sensitivity and specificity vary significantly, with a reduced accuracy at PSA levels of less than $1 \mathrm{ng} / \mathrm{ml}[1,2]$. This can result in delays in salvage therapy or delayed diagnoses, and thus has driven research into alternative imaging modalities with the aim of improving patient care.

Although the first publication mentioning prostate-specific membrane antigen (PSMA) was in 1982, PSMA has only recently started to be used to aid imaging [3]. This cell surface antigen is highly specific for prostate cells and prostatic malignant tissue, and antibodies to PSMA have also been shown to have affinity to tumour vascular endothelium [4-6]. Radio-labelling PSMA with a positron emitting isotope of Gallium, has created a new tracer with the intention of improving the detection rates of PET scanning, especially at lower PSA levels [7].

Bluemel et al. [8] published an article in Clinical Nuclear Medicine Journal that looked at the detection rates of Gallium tracer PSMA PET scans compared with standard choline PET. Detection rates were higher in PSMA PET, finding that this modality detected recurrence sites in $43.8 \%$ of Choline negative PET investigations. This is especially significant as the sub-analysis for PSA level found $28.6 \%$ of these cases had PSA $<1 \mathrm{ng} / \mathrm{ml}[8]$.

Morigi et al. [9] showed statistically significant data proving that at $<0.5 \mathrm{ng} / \mathrm{ml}$, PSMA PET was more accurate than $18 \mathrm{~F}$ Choline PET, with a $37.5 \%$ improved detection rate $(\mathrm{p}=0.03)$.

Most importantly, PSMA PET scans are improving patient treatment. Morigi et al. [9] found PSMA PET positive scan in previous choline negative rates of $54 \%$, and all of these patients then went on to have moderate-major management alterations to their clinical care.

The review by Pfister et al. [10] observing 5-year biochemical free survival rates, confirmed improved outcomes of salvage radiotherapy in

Copyright: ( 02018 Hampson A. This is an open-access article distributed under the terms of the Creative Commons Attribution License, which permits unrestricted use, distribution, and reproduction in any medium, provided the original author and source are credited.

patients treated with PSA $<0.5 \mathrm{ng} / \mathrm{mL}$. This emphasises the requirement for early detection of prostatic recurrence at low PSA levels.

If we can detect oligo-metastatic recurrence of prostate cancer earlier and at lower PSA levels, then accurate and suitable treatment plans can be implemented sooner, giving the patient, and their treatment, a higher chance of success.

\section{References}

1. Krause BJ, Souvatzoglou M, Tuncel M, Herrmann K, Buck AK, et al. (2008) The detection rate of $[11 \mathrm{C}]$ choline-PET/CT depends on the serum PSA-value in patients with biochemical recurrence of prostate cancer. Eur J Nucl Med Mol Imaging 35: 1823. [Crossref]

2. Picchio M, Briganti A, Fanti S, Heidenreich A, Krause BJ, et al. (2011) The role of choline positron emission tomography/computed tomography in the management of patients with prostate-specific antigen progression after radical treatment of prostate cancer. Eur Urol 59: 51-60. [Crossref]

3. Frankel AE, Rouse RV, Herzenberg LA (1982) Human prostate specific and shared differentiation antigens defined by monoclonal antibodies. Proc Natl Acad Sci U S A 79: 903-907. [Crossref]

4. Liu H, Moy P, Kim S, Xia Y, Rajasekaran A, Navarro V, et al. (1997) Monoclonal antibodies to the extracellular domain of prostate-specific membrane antigen also react with tumor vascular endothelium. Cancer Res 57:3629-3634.

5. Mannweiler S, Amersdorfer P, Trajanoski S, Terrett JA, King D, et al. (2009) Heterogeneity of prostate-specific membrane antigen (PSMA) expression in prostate carcinoma with distant metastasis. Pathol Oncol Res POR 15:167-172.

6. Silver DA, Pellicer I, Fair WR, Heston WD, Cordon-Cardo C (1997) Prostate-specific membrane antigen expression in normal and malignant human tissues. Clin Cancer Res Off J Am Assoc Cancer Res 3:81-85.

7. Afshar-Oromieh A, Haberkorn U, Eder M, Eisenhut M, Zechmann CM (2012) [68Ga] Gallium-labelled PSMA ligand as superior PET tracer for the diagnosis of prostate cancer: comparison with 18F-FECH. Eur J Nucl Med Mol Imaging 39:1085-1086.

8. Bluemel C, Krebs M, Polat B, Linke F, Eiber M, et al. (2016) 68Ga-PSMA-PET/CT in Patients With Biochemical Prostate Cancer Recurrence and Negative 18F-CholinePET/CT. Clin Nucl Med 41: 515-521. [Crossref]

9. Morigi JJ, Stricker PD, van Leeuwen PJ, Tang R, Ho B, Nguyen Q, et al. (2015) Prospective Comparison of 18F-Fluoromethylcholine Versus 68Ga-PSMA PET/CT in Prostate Cancer Patients Who Have Rising PSA After Curative Treatment and Are Being Considered for Targeted Therapy. J Nucl Med Off Publ Soc Nucl Med 56:1185-1190.

10. Pfister D, Bolla M, Briganti A, Carroll P, Cozzarini C, Joniau S, et al. (2014) Early Salvage Radiotherapy Following Radical Prostatectomy. Eur Urol 65:1034-1043.

${ }^{\star}$ Correspondence to: Nikhil Vasdev, Consultant Urological Surgeon / Senior Clinical Lecturer, Department of Urology, Lister Hospital Stevenage, UK, E-mail: Nikhil.Vasdev@nhs.net

Received: September 14, 2018; Accepted: September 21, 2018; Published: September 27, 2018 